\title{
POLÍTICAS PÚBLICAS E O PAPEL DA GEOGRAFIA
}

\section{Public Policy and the Role of Geography}

\author{
Prof ${ }^{0}$ Angelo Serpa \\ Universidade Federal da Bahia, Instituto de Geociências, Departamento de Geografia.
}

Rua Barão de Geremoabo, s/n, Campus Universitário de Ondina, CEP:40170-290 - Salvador, BA - Brasil

Tel/Fax: (+55 71) 32838569 / 32838526 - angserpa@ufba.br

\section{$a_{a} \boldsymbol{a}_{a a}$}

\begin{abstract}
Resumo
Pretende-se, com o presente artigo, discutir como a Geografia pode contribuir em relação à formulação e à implementação de políticas públicas. Parte-se do pressuposto de que, se há aqui alguma especificidade do conhecimento geográfico relativa às políticas públicas, ela está na dimensão espacial que permeia a temática, fazendo pensar em questões como a distribuição espacial dos programas, planos e projetos no território nacional e as desigualdades regionais advindas da formulação e da implementação das políticas públicas no Brasil. Acredita-se que a Geografia tem muito a colaborar e a dizer também na questão da articulação de escalas e recortes espaciais, muitas vezes ignorada ou relegada a um segundo plano, quando se trata de políticas públicas que buscam articular programas com participação de diferentes níveis de governo no país. O texto está dividido em cinco partes, abordando-se as relações entre políticas públicas, Geografia e cidadania; apresentando as possibilidades de uma abordagem dialética e cultural das políticas públicas no contexto brasileiro; discutindo-se a questão da participação popular na elaboração/implementação de políticas; e, finalmente, refletindo como as diferentes ideias de cultura podem nortear processos de regionalizacão institucional e políticas de desenvolvimento territorial. Conclui-se que as variáveis que estão em jogo para a análise das políticas públicas no Brasil por um viés geográfico são as escalas, o território, o poder, a região, a cultura, a identidade e a cidadania. Elas oferecem a oportunidade para a Geografia avançar nessa discussão, norteando-se por uma abordagem dialética e cultural para a análise das políticas públicas no contexto brasileiro.

Palavras-chave: políticas públicas; Geografia; cidadania; regionalização.
\end{abstract}

\begin{abstract}
The present paper intends to discuss how Geography may contribute to the formulation and implementation of public policies. It is based on the assumption that, when geographic knowledge makes any contribution to public policy, it is limited to the spatial dimension, being related to questions such as the spatial distribution of plans, programs, and projects on a national scale, and the regional disparities resulting from the formulation and implantation of public policies in Brazil. However, Geography appears to have much to offer in terms of the articulation of scales and spatial profiling, which is often ignored or relegated to a low priority in the context of public policies that aim to articulate the participation of different levels of government within the country. The most important variables for the analysis of public policy in Brazil from a geographical perspective appear to be scale, territory, power, region, culture, identity, and citizenship. These variables provide Geography with the means to advance in this discussion, underpinned by a dialectic and cultural approach to the analysis of public policy in the Brazilian context.
\end{abstract}

Key words: public policies, Geography, citizenship, regionalization.

\section{Resumen}

Se pretende, con el presente artículo, discutir como la Geografía puede contribuir en relación a la formulación e implementación de políticas públicas. Se parte del presupuesto de que, se hay aquí alguna especificidad del conocimiento geográfico relativa a las políticas públicas, la que está en la dimensión espacial que coloca la temática, haciendo pensar en cuestiones como la distribución espacial de los programas, planes y proyectos en el territorio nacional y las desigualdades regionales procedentes de la formulación e implementación de políticas públicas en el Brasil. Se piensa que la Geografía tiene mucho a colaborar y a decir también en la cuestión de la articulación de escalas y recortes espaciales, muchas veces ignorada o relegada a un segundo plano, cuando se trata de políticas públicas que buscan articular programas con participación de diferentes niveles de gobierno en el país. Se concluye que las variables que están en juego para el análisis de las políticas públicas en Brasil por una mirada geográfica son las escalas, el territorio, el poder, la región, la cultura, la identidad y la ciudadanía. Las ofrecen la oportunidad para la Geografía avanzar en esa discusión, siguiéndose por un abordaje dialéctica y cultural para el análisis de las políticas públicas en el contexto brasileño.

Palabras-clave: políticas públicas, Geografía, ciudadanía, regionalización. 


\section{INTRODUÇÃO}

Há muitas maneiras de se abordar a temática das políticas públicas, mas a proposta dessa mesa redonda parece clara: o que a Geografia tem a dizer, a contribuir, em relação à formulação e à implementação de políticas públicas? Em especial, o que a Geografia brasileira pode fazer nesse campo ao se debruçar sobre como vêm sendo formuladas e implementadas as políticas públicas no território nacional?

Certamente se há aqui alguma especificidade do conhecimento geográfico relativa às políticas públicas, ela está na dimensão espacial que permeia a temática, fazendo pensar em questões como a distribuição espacial dos programas, planos e projetos no território nacional e as desigualdades regionais advindas da formulação e da implementação das políticas públicas no Brasil.

A Geografia tem muito a colaborar e a dizer também na questão da articulação de escalas e recortes espaciais, muitas vezes ignorada ou relegada a um segundo plano, quando se trata de políticas públicas que buscam articular programas com participação de diferentes níveis de governo no país. A questão não é nova, todavia. Sem dúvida, o problema da articulação de escalas e recortes na formulação/implementação de políticas públicas aparece, por exemplo, na obra de Milton Santos (1994), quando este autor afirma que o nível de intencionalidade do governo federal e sua abrangência de atuação não são os mesmos para os governos estaduais e municipais.

Em um trabalho de Racine, Raffestin e Ruffy, de 1983, a questão vai ser abordada sob a perspectiva da "escala como mediadora da ação", com o objetivo de lançar as bases para uma política ativa de organização do território: segundo eles, isto implicaria necessariamente em uma tomada de consciência da dialética das escalas geográficas e cartográficas que sustenta uma relação de poder com o território e com o que ele contém.

A questão da escala suscita também uma discussão sobre o papel das representações espaciais como norteadoras de políticas públicas, ou, para usar os termos colocados pelos autores citados anteriormente, sobre o papel das diversas "caricaturas" ou dos diversos modelos espaciais que vão subsidiar planos para ações futuras:

A escolha de uma representação funcional dependerá da relação de poder que se quer ter, levados em conta os recursos disponíveis e os custos que se pode aceitar. Aquele que age realiza uma interseção entre um conjunto de utilidade e um conjunto representado; quer dizer então que ele atualiza a relação de poder e que potencializa a relação funcional. O domínio das escalas é, portanto, um elemento prévio a toda a ação. É talvez essa a ocasião de convidar os geógrafos a descobrir uma 'escala das preocupações humanas' que transcendem as preocupações técnicas daqueles que somente se interessam pelas variações das escalas geográficas em si mesmas (RACINE, RAFFESTIN, RUFFY, 1983, p. 134).

A aplicação de teorias e modelos de localização e de desenvolvimento regional tem uma tradição de décadas no Brasil e se consolidou no âmbito da produção do conhecimento, especialmente na Nova Geografia, como uma possibilidade de operacionalização de uma perspectiva geográfico-econômica para a formulação de políticas de desenvolvimento territorial. Dentro dessa perspectiva, e nas palavras de Silva (1976), tais modelos partiam do

pressuposto básico de que o processo de desenvolvimento regional depende do funcionamento do sistema econômico-social a nível espacial e de que este funcionamento, por sua vez, é explicado pela localização e interação das atividades econômicas e sociais sobre o espaço geográfico (SILVA, 1976, p. 1).

Fala-se aqui de teorias de localização industrial, do modelo dos pólos de crescimento, das teorias das localidades centrais e centro-periferia, de modelos como aquele do estado isolado (para explicar a localização de atividades agrícolas) ou do desenvolvimento regional induzido, ou ainda da teoria da propagação das ondas de inovação. Se tais modelos e teorias não foram totalmente 
superados no âmbito da produção do conhecimento geográfico, deve-se reconhecer que foram bastante questionados no âmbito da disciplina nas últimas décadas.

Tais questionamentos fizeram surgir abordagens culturais e dialéticas para a questão das desigualdades sócio-espaciais no país, que a aplicação de tais modelos sob a forma de políticas públicas no território nacional não logrou equacionar a bom termo. São essas abordagens que abrem novas perspectivas para a Geografia como conhecimento básico e fundamental para a formulação e a implementação de políticas públicas nos mais variados recortes do território nacional, como passamos a analisar a seguir.

\section{POLÍTICAS PÚBLICAS, GEOGRAFIA E CIDADANIA}

Um modelo econômico, tomado isoladamente, e por melhor que ele pareça, não bastará para que os grandes problemas da nação sejam solucionados. A sociedade é mais que a economia. Um modelo que apenas se ocupe da produção em si mesma (ainda que as diversas instâncias econômicas produtivas estejam incluídas: circulação, distribuição, consumo), nem mesmo para a economia será operacional. A sociedade também é ideologia, cultura, religião, instituições e organizações formais e informais, território, todas essas entidades sendo forças ativas. $\mathrm{O}$ econômico pode parecer independente em seu movimento, mas não o é. A interferência das demais entidades que formam o corpo da nação corrige ou deforma ou, simplesmente, modifica as intenções do planejamento econômico, sobrepondo-lhe a realidade social (SANTOS, 1992, p. 95-96).

A longa citação que abre esta seção mostra quão longe foram os questionamentos na Geografia brasileira às políticas públicas norteadas por critérios estritamente econômicos, como mencionado na introdução deste artigo. Em "O Espaço do Cidadão", Milton Santos demonstra o que poderia nortear a constituição de uma Geografia muito mais política, que econômica, uma Geografia genuinamente brasileira.

Embora reconheça a cidadania mutilada no contexto brasileiro, Santos vai lançar com esta obra as bases de uma Geografia política voltada para os direitos universais, bem como para os direitos sociais não conquistados, a saber: o direito a um teto, à comida, à educação, à saúde, ao trabalho, ao lazer e à justiça. Mas, aqui, o direito à liberdade é central, o que torna sua Geografia uma geopolítica que também incorpora uma dimensão social.

Para Milton Santos, no Brasil, a noção de direitos políticos foi desrespeitada, frequentemente pisoteada ou anulada. De acordo com Santos, muitos pobres acreditaram nos slogans com que se popularizou o discurso cientificista dos economistas e terminaram ainda mais pobres. Isso mostra também que o modelo político foi instrumental para o modelo econômico, este último acenando às massas com esperanças sedutoras. Ou seja, as massas foram despertadas para a necessidade, o interesse e a vantagem da ampliação do consumo, mas não para o exercício pleno da cidadania (SANTOS, 1992).

Ao opor a necessidade e o consumo à liberdade e à cidadania, Milton Santos vai enfatizar o caráter político de sua Geografia, já que, como Hannah Arendt (2000), reconhece que a liberdade situa-se exclusivamente na esfera política, enquanto a necessidade é um fenômeno pré-político, próprio da esfera privada. Em Arendt, a ascendência de uma esfera social, que não é nem privada nem pública, é um fenômeno relativamente novo, cuja origem coincidiu com o surgimento da era moderna e que encontrou sua forma política no estado nacional. Sob essa ótica, a "economia nacional" ou a "economia social" substituem a "política", indicando o surgimento de administrações domésticas coletivas, os governos nacionais (ARENDT, 2000). Mas, o que é estritamente econômico ou social está relacionado com interesses privados, de grupos e indivíduos, não é assunto político.

Milton Santos vai mais longe ao admitir que se pode atingir a liberdade através da necessidade, pressupondo a emergência de um período popular da história, cujos protagonistas serão os mais 
pobres, aqueles que ainda não alcançaram a esfera do consumo de massa. Essas reflexões apontam um caminho para a Geografia contemporânea para pensar as políticas públicas no contexto brasileiro, como passamos a analisar nas próximas seções.

\section{POR UMA ABORDAGEM DIALÉTICA E CULTURAL DAS POLÍTICAS PÚBLICAS NO CONTEXTO BRASILEIRO}

Um novo caminho para uma abordagem a um só tempo dialética e cultural das políticas públicas sob um viés geográfico passa necessariamente pela articulação dos conceitos de política e cultura. Parte-se, aqui, da premissa básica de que cultura e política são fenômenos da esfera pública, pois ambos, como indicado por Hannah Arendt, baseiam-se na capacidade de julgamento e de decisão. Cultura indica que arte e política, não obstante seus conflitos e tensões se inter-relacionam e até são dependentes. Em juízos estéticos, tanto quanto em juízos políticos, toma-se uma decisão. A atividade do gosto decide como o mundo deverá parecer, independentemente de sua utilidade e dos interesses que tenhamos nele. Visto assim, o gosto é a capacidade política que humaniza o belo e cria uma "cultura" (ARENDT, 2002).

A cultura é um motivo de conflito de interesses nas sociedades contemporâneas, um conflito pela sua definição, pelo seu controle, pelos benefícios que assegura (SANTOS, 1988), o que, em última instância, enfatiza as relações entre cultura e poder e o caráter político da cultura.

Para Habermas (1984), a "cultura" que é difundida pelos meios de comunicação de massa é uma "cultura de integração", integrando informação e raciocínio através de estruturas suficientemente elásticas para assimilar também elementos de propaganda, como espécies de super-slogans. É assim que esfera pública vai assumindo funções de propaganda, já que pode ser utilizada como meio de influir política e economicamente. Mas, nesse processo, quanto mais apolítica se torna a esfera pública, tanto mais aparenta estar privatizada.

Se negarmos como Mitchell (1996) o caráter ontológico de “cultura", então temos que também admitir com ele que o que existe em geral é uma ideia de cultura apropriada e disseminada através e pelas estruturas sociais de produção e reprodução. Cultura é linguagem que se traduz em códigos, mas precisamos, sobretudo, entender como surge a ideia de cultura (ou as ideias de cultura), o porquê de sua força, relacionando-a com as estratégias e táticas dos agentes que produzem os espaços dos bairros, cidades e regiões, o espaço da nação.

Mitchell (op. cit.) sugere uma agenda de pesquisa para uma abordagem cultural da Geografia, que deveria buscar elucidar como grupos que consolidaram historicamente seu poder e sua hegemonia instrumentalizaram suas ideias de cultura. Poder-se-ia examinar, por exemplo, como as guerras étnicas e os processos civilizatórios se alimentam das diferenças culturais, valorizando-as como "atributos de um povo" e consolidando, ao mesmo tempo, a existência de "subclasses" e de "subculturas". Poder-se-ia, assim, também entender as "geografias da cultura" como processos sociais e políticos reais, como práticas de representações sociais.

O ponto de partida para qualquer análise em Geografia Política e Cultural deve ser, portanto, o de compreender como a "ideia de cultura funciona em meio e através de relações sociais de produção e reprodução" (MITCHELL, 1996, p. 46). Com as leis do mercado penetrando na substância das manifestações culturais e tornando-se imanentes a elas como leis estruturais, tudo, ou quase tudo - difusão, escolha, apresentação e criação - se orienta, nos setores amplos da cultura, de acordo com estratégias de venda do mercado. É uma lógica homogeneizante, que exprime uma posição "de força", afirmando a universalidade dos valores culturais das classes médias urbanas, se apropriando de tudo que parece digno de ser extirpado das classes populares, num processo de "vampirismo cultural". 


\section{POLÍTICAS PÚBLICAS E A QUESTÃO DA PARTICIPAÇÃO}

A inclusão da sociedade civil nos processos decisórios está presente hoje tanto nos discursos políticos como nos meios de comunicação de massa: "A expressão 'participação social' parece estar em voga" (SOTO, CANEDO, OLIVEIRA, SALGADO, 2010, p. 25). No entanto, dos planos diretores, tornados obrigatórios para a maioria dos municípios brasileiros pela Constituição de 1988, aos programas que articulam diferentes esferas de governo, a participação da população nos processos decisórios ainda é incipiente e irregular no Brasil.

A questão suscita uma reflexão aprofundada sobre a questão da legitimidade das representações da sociedade civil e do Estado nos conselhos, colegiados e conferências, em suma, nos diferentes fóruns de participação, bem como sua institucionalização e seu papel na formulação e na implementação/gestão de políticas públicas nos municípios, estados e regiões do país, se possuem caráter consultivo ou deliberativo. Se analisado o histórico das políticas públicas no Brasil, é mister constatar que "estas foram quase sempre decididas de forma autoritária pelos poderes governamentais, com pouca ou quase nenhuma participação da sociedade civil" (SOTO, CANEDO, OLIVEIRA, SALGADO, 2010, p. 27).

Também aqui, a Geografia tem muito a dizer e a colaborar sobre a temática, senão vejamos: Um primeiro ponto de reflexão diz respeito à proporcionalidade entre os diversos segmentos da sociedade civil e do Estado, pensando-se nos coeficientes percentuais mínimos destes segmentos. É importante verificar, por exemplo, para os diferentes recortes espaciais analisados, se tais coeficientes são norteados por resoluções legislativas específicas. Uma segunda questão é se de fato os recortes espaciais utilizados vêm se constituindo em uma base espacial adequada para aproximar os segmentos da sociedade das instâncias de planejamento e gestão territoriais em um processo efetivo e legítimo de participação popular.

No Orçamento Participativo de Porto Alegre, por exemplo, experiência tida como exitosa e emblemática, trabalhos científicos apontam para o descompasso entre os espaços de vivência da população (bairros) e os espaços tomados como base para determinar os percentuais de participação das lideranças comunitárias, em geral "pinçadas" de espaços abstratos maiores como as Regiões Administrativas. Esses espaços não se legitimam no cotidiano dos habitantes da cidade e colocam em xeque a representatividade das comissões de discussão e decisão das políticas públicas resultantes do Orçamento Participativo (SOUZA, 2000).

Concorda-se com Souza (2000), para quem, "similarmente a outros tantos fenômenos sociais, também o orçamento participativo tem sido estudado sem que os seus condicionantes e as suas consequências espaciais sejam devidamente considerados" (p. 2). Para o autor, os orçamentos participativos combinam, de modo diferenciado, uma dimensão espacial com uma dimensão "setorial":

A dinâmica básica e originária privilegia a dimensão espacial na organização do processo, em que o município é dividido em setores geográficos (impropriamente chamados de "regiões"), os quais são os recortes espaciais que servem de referência para a mobilização da população e o processo de eleição de prioridades e escolha dos delegados que representarão diretamente a população junto à Prefeitura. Esses recortes expressam poder, definem fronteiras, condicionam e orientam a participação; eles definem territórios. Como são as territorializações geradas, negociadas e "atualizadas" na esteira da prática política? Até que ponto esses recortes territoriais espelham autênticos sentimentos de lugar? (ibidem, p. 6 , grifos nossos).

Souza dá continuidade a suas reflexões, questionando, inclusive, a legitimidade e adequação dos critérios de definição dos recortes territoriais que fundamentam o processo de participação, formulando outras questões que também são (muito) pertinentes para a reflexão aqui proposta:

Os recortes territoriais consideram as tradições de organização da população ou são, pelo contrário, em maior ou menor grau, uma imposição "de cima para baixo" de uma malha territorial? Em que medida 
sentimentos "legítimos" de lugar estão contemplados (ou não) nos recortes territoriais adotados? Quão forte é a identificação da população com cada recorte territorial de referência? Como essa identificação maior ou menor pode condicionar a dinâmica participativa (menor poder catalítico da dimensão espacial...)? De que modo recortes territoriais diferentes condicionam diferentemente o processo? (ibidem, p. 7).

A questão da participação social na elaboração/implementação/gestão das políticas públicas recoloca a questão da cidadania e sua dimensão espacial, do modo como isso é discutido por Santos (1992), já que "é impossível imaginar uma cidadania completa que prescinda do componente territorial" (SANTOS, 1992, p. 116). E é claro que aqui a questão das escalas e da articulação de recortes espaciais reaparece com toda força, exigindo um enfoque novo para as ações dos governos, em seus diferentes níveis, na forma de políticas públicas: "Caberia, em primeiro lugar, bem definir as entidades territoriais, segundo uma tipologia de serviços a prover e de ações a desenvolver" (ibidem, p. 118). E isso também é válido para se pensar nas diferentes realidades regionais do país:

As populações locais devem ter direito à palavra, não apenas como parcela viva da nação ou de um Estado, mas como membros ativos de uma realidade regional que lhes diz diretamente respeito, e sobre a qual não dispõem de um recurso institucional para que sua voz seja ouvida. Falta às regiões câmaras representativas regionais, cuja tarefa essencial seria a de propor os modos próprios de regulação da vida regional (...) Não seriam apenas as regiões metropolitanas a merecer as regalias de um nível próprio de governo, mas todos os sub-espaços regionais. Resta, sem dúvida, a questão da delimitação geográfica, da delimitação das competências e da natureza desse poder regional aqui proposto (SANTOS, 1992, p. 119).

Segundo Santos, uma vez aceitos estes princípios, os critérios para sua implementação seriam encontrados a partir das diferentes realidades sócio-econômico-territoriais do país. Baseando-se nestas ideias, passamos a analisar, na próxima seção, o caso particular de políticas de regionalização institucional e de desenvolvimento cultural e territorial que vêm sendo implementadas no Brasil e mais particularmente no Estado da Bahia, objeto de pesquisas realizadas no âmbito das atividades do Grupo Espaço Livre de Pesquisa-Ação, da Universidade Federal da Bahia.

\section{QUANDO A CULTURA NORTEIA PROCESSOS DE REGIONALIZAÇÃO INSTITUCIONAL E POLÍTICAS DE DESENVOLVIMENTO TERRITORIAL}

No âmbito federal, desde 2002, programas dos Ministérios da Cultura (MINC) e do Desenvolvimento Agrário (MDA) vêm sendo elaborados e implementados na perspectiva de valorização do componente territorial e das identidades regionais, buscando aproximar a sociedade civil das esferas de governo a partir de uma nova perspectiva de institucionalização da participação social na gestão de políticas públicas no território nacional.

Um processo de identificação de territórios rurais foi deflagrado, a partir de 2003, pela Secretaria de Desenvolvimento Territorial (SDT) do MDA, para nortear as políticas públicas para o setor agrícola nacional, especialmente naqueles ligados à agricultura familiar, atendidos atualmente pelo Programa Territórios Rurais. De acordo com o site do Programa, a Secretaria vem atuando

em 164 territórios rurais de todo País, apoiando a organização e o fortalecimento institucional dos atores sociais locais na gestão participativa. O objetivo é garantir o atendimento às necessidades básicas da população, bem como acelerar processos locais e subregionais que ampliem as oportunidades de geração de renda de forma descentralizada e sustentável, articulados às redes de apoio e cooperação solidária (http://www.mda.gov.br).

Assim, os territórios rurais passam a ser a unidade de planejamento das políticas de desenvolvimento territorial no Brasil. Na Bahia, o MDA atua de duas maneiras: apoiando diretamente 
treze territórios e dando suporte às políticas estaduais como um todo. A política dos territórios como unidades de planejamento é o que vai nortear também o lançamento pelo governo federal do programa "Territórios da Cidadania" em fevereiro de 2008, que tem como objetivos

promover o desenvolvimento econômico e universalizar programas básicos de cidadania por meio de uma estratégia de desenvolvimento territorial sustentável. A participação social e a integração de ações entre Governo Federal, estados e municípios são fundamentais para a construção dessa estratégia (http:// www.territoriosdacidadania.gov.br/).

No âmbito do MINC, a implantação e o desenvolvimento de um Sistema e de um Plano Nacionais de Cultura, bem como a aprovação do Projeto de Emenda Constitucional (PEC) 150 assumiram nos últimos anos uma posição central na formatação de políticas de Estado, que, "transcendendo governos, possam viabilizar políticas nacionais mais permanentes que coloquem em xeque as instabilidades", uma das "tradições que marcam as políticas culturais nacionais no país" (RUBIM, 2010, p. 16). Segundo Rubim, o Ministério vem formatando políticas culturais em parceria com estados, municípios e sociedade civil para consolidação de um Sistema Nacional de Cultura, que se constitui como uma peça "vital para a consolidação de políticas e de estruturas, pactuadas e complementares, que viabilizem a existência de programas culturais de prazos médios ou longos, portanto não submetidas às intempéries conjunturais" (RUBIM, 2010, p. 17).

No Estado da Bahia, no início de 2007, o Fórum Baiano de Agricultura Familiar reivindicou o reconhecimento, a adoção e o estabelecimento de 26 Territórios de Identidade, em substituição às Regiões Econômicas, como diretriz básica do planejamento público estadual junto ao secretário do planejamento estadual e sua equipe. A partir de então, outras secretarias de governo foram envolvidas no processo, o que resultou na elaboração de um mapa com as novas regiões do Estado, que passou a ser utilizado como "instrumento de orientação para a promoção do desenvolvimento social, com equidade e em todo o território baiano", norteando também a concepção do Plano Plurinual PPA 2008/2011 (http://www.seplan.ba.gov.br). O processo de regionalização, adotado paulatinamente pelo governo estadual em seu conjunto, se norteou por procedimentos que pretendiam "revelar" os diferentes territórios, inspirados na regionalização do país em Territórios Rurais pelo MDA.

Trata-se de um processo de regionalização institucional que vem influenciando também a distribuição dos recursos de fomento à cultura no Estado da Bahia, visando a uma desconcentração dos investimentos públicos da Região Metropolitana de Salvador em direção ao interior do Estado. Trata-se aqui também de rediscutir o papel do Estado no fomento à cultura, visando ao apoio de manifestações culturais populares, até então preteridas em função de manifestações da cultura dita "erudita". Segundo a Secretaria da Cultura do Estado (SECULT), a ideia, com a nova regionalização proposta, é a promoção do desenvolvimento cultural de forma descentralizada, "incentivando a implantação de modelos de gestão cultural que promovam a sustentabilidade das ações de desenvolvimento nos Territórios de Identidade do Estado da Bahia" (www.cultura.ba.gov.br).

Observa-se, assim, o deslocamento de foco do campo econômico para o campo cultural em um processo de regionalização institucional no âmbito estadual, fortemente inspirado em políticas públicas federais, que também vão eleger a cultura como principal critério norteador. A nova regionalização, que substitui a anterior em regiões econômicas, foi pensada não somente como instância aglutinadora e articuladora de políticas estaduais: Os territórios de identidade foram tomados, desde então, como unidades de planejamento e controle social das ações de governo, o que implica no relacionamento constante e permanente entre os colegiados territoriais constituídos, na execução de programas, planos e projetos. A estratégia é a de aproximação entre os representantes da sociedade e do governo estadual, em um clima otimista em relação à participação popular no processo de planejamento regional.

A política territorial desenvolvida no Estado da Bahia tem caráter finalista, se constituindo como um instrumental que vai dar suporte a uma integração das políticas setoriais, inclusive apoiando a 
implementação do programa federal Territórios da Cidadania. A Coordenação Estadual dos Territórios (CET) articula em rede os colegiados territoriais no Estado da Bahia, estimulando o diálogo entre os territórios e a consolidação/o fortalecimento dos colegiados, funcionando também como mediadora de conflitos. A experiência foi ampliada para o país, com a criação de uma Coordenação Nacional dos Territórios de Cidadania (CNT): Uma comissão executiva correu os Estados, a partir de 2008, articulando uma rede nacional, integrando as 25 redes Estaduais de colegiados. Na Bahia, os territórios têm autonomia para definir a formação de seus colegiados: Alguns são institucionalizados e possuem CNPJ, outros colegiados optaram por não seguir o caminho da institucionalização; alguns colegiados são formados por $1 / 3$ do poder público e $2 / 3$ da sociedade civil, outros são paritários.

Os colegiados territoriais assim constituídos foram uma instância aglutinadora fundamental para a discussão do Plano Plurianual de Investimentos. Para a constituição do Conselho de Acompanhamento do plano (CAPPA), cada uma das unidades territoriais do Estado elegeu quatro representantes, dois titulares e dois suplentes, para acompanhar a execução do orçamento. O CAPPA se reúne ordinariamente a cada três meses em Salvador e o governo estadual arca com as despesas de passagens, hospedagem e alimentação de todos os representantes territoriais durante os dois dias de duração de cada encontro. Percebe-se, portanto, uma preocupação do governo estadual em envolver os colegiados territoriais na discussão e na elaboração do PPA, o que é interessante, pois uma regionalização institucional de base "cultural" vai embasar os investimentos públicos nas diferentes unidades territoriais. Porém, uma análise da distribuição dos recursos por território do PPA 2008-2011 demonstra que a Região Metropolitana de Salvador ainda concentra a maior parte dos investimentos $(39,46 \%)$, aumentando, inclusive, sua participação nos recursos investidos em relação ao PPA 2004-2007, no qual a distribuição se fazia por eixos de desenvolvimento e o eixo metropolitano concentrava $29,0 \%$ do total de investimentos.

Na Secretaria de Cultura estadual, o desafio principal é a constituição de um sistema de gestão da cultura com atuação autônoma e articulada das três esferas de governo. Na justificativa da Proposta de Emenda à Constituição - PEC 416/2005, que cria o Sistema Nacional de Cultura, os municípios e as instâncias locais de decisão aparecem com destaque, evidenciando que, também nas políticas de desenvolvimento cultural no Estado da Bahia, houve uma transposição de um modelo adotado em nível federal para o nível estadual:

As políticas públicas locais têm um papel central na ecologia cultural, na qual a cidade é o território do diálogo entre os diferentes e do respeito à pluralidade cultural. Da mesma forma que se busca a universalização da oferta de educação, é preciso que se trabalhe pelo acesso irrestrito aos bens culturais. Um sistema universalizador de gestão da cultura deve acolher, como elementos-chave, a criação dos conselhos de cultura, dos fundos de cultura e das formas de participação democrática e descentralizada dos produtores culturais e das comunidades em geral (http://www.camara.gov.br/sileg/integras/316130. pdf).

Nessa passagem, do federal ao estadual, a SECULT vem assessorando as prefeituras para a articulação de sistemas municipais, seguindo o modelo adotado pelo MINC. Porém, uma das maiores limitações para a implementação de políticas de desenvolvimento territorial e cultural norteadas pelos princípios da descentralização e da municipalização é a fragilidade institucional e técnica de muitas das municipalidades do Estado da Bahia. Esse fato é, aliás, um dos principais argumentos, entre os técnicos da Secretaria de Planejamento estadual, para a constituição de consórcios municipais, que visam, em última instância, a ampliar a capacidade de gestão dos municípios e facilitar a execução, no âmbito municipal, das políticas federais e estaduais. Ou seja, são as municipalidades que executam as políticas e, para garantir isso, é necessário buscar um incremento de suas capacidades a partir da articulação entre os municípios.

A articulação em rede das instituições públicas e a constituição de sistemas setoriais, como no caso da área cultural, para a execução das políticas de desenvolvimento territorial e cultural é, 
sem dúvida, um avanço. Mas há aqui muitos desafios a serem enfrentados. O primeiro deles diz respeito à organização da sociedade civil nos territórios e municípios. As políticas parecem avançar mais naqueles territórios e municípios onde a participação e a organização da sociedade regional já eram significativas, antes mesmo da nova regionalização do Estado em Territórios de Identidade. É o caso dos territórios onde o governo Federal, através do Ministério do Desenvolvimento Agrário, já atuava desde 2003 com o Programa Territórios Rurais. A partir de 2008, os nove territórios de identidade apoiados pelo Programa Territórios da Cidadania, também do governo federal, parecem se organizar mais rápido e com mais participação da sociedade civil nos colegiados territoriais.

Finalmente, o desafio maior a ser enfrentado é a consolidação dos territórios como unidades de gestão territorial e espaços de vivência da população, como defendido por Cardoso (2003) para o recorte das bacias hidrográficas, quando afirma que há uma diferença fundamental entre reconhecer uma bacia e se identificar com ela. Ou seja, também para os territórios, guardadas as especificidades de regionalizações baseadas em critérios diferenciados, a máxima de Cardoso pode ser aplicada. Pensando-se assim, é necessário dar um passo além do reconhecimento em direção a uma identificação mais profunda e consolidada da população regional com as novas unidades territoriais. Para que isso ocorra é necessário incorporar paulatinamente as representações espaciais dos segmentos regionais envolvidos, como já vem acontecendo através das assembléias dos colegiados territoriais e das conferências estaduais de cultura.

\section{CONSIDERAÇÕES FINAIS}

Os resultados preliminares das pesquisas por nós desenvolvidas na Bahia, apresentados na última seção, mostram que são muitas as possibilidades para a análise geográfica das políticas públicas no Brasil. Com o desenvolvimento do projeto de pesquisa "Cultura e Poder na Formulação

de Políticas Públicas de Desenvolvimento Territorial e Cultural: Um Estudo sobre Articulaçâo de Escalas Geográficas e Regionalização Institucional no Estado da Bahia”, em andamento, buscamos compreender como cultura e poder se articulam nos embates entre os diferentes agentes produtores do espaço urbano e regional, que vão redundar em políticas específicas em forma de programas, planos e projetos. A questão central aqui é analisar de que modo os municípios baianos vão se articular em torno de unidades territoriais resultantes de novos processos de regionalização institucional. Ou, em outras palavras, como territórios são articulados enquanto escalas de abordagem numa arena política que coloca a cultura e as "identidades regionais" no centro de um processo de regionalização institucional do território estadual. Questionamos também até que ponto um processo de regionalização assim, que priorize uma abordagem sócio-cultural para o conceito de região ("territórios de identidade"), em substituição a uma abordagem anterior, estritamente econômica, pode aproximar a atuação da sociedade e do Estado na articulação de políticas culturais e de desenvolvimento regional.

Para aprofundamento de nossas pesquisas, buscamos distinguir as regionalizações (e regionalismos) que se constroem no dia a dia dos habitantes das regiões e que vão consolidando uma "consciência regional" como reflexo e condição de uma apropriação simbólica e material do território, e as regionalizações institucionais como base para estratégias estatais de desenvolvimento regional. $\mathrm{Na}$ verdade, o desafio para as políticas públicas é a construção de convergências entre esses dois processos, que são distintos e implicam, ambos, em rebatimentos evidentes no planejamento territorial. A regionalização institucional resulta, portanto, da atuação do Estado, ao contrário daquela regionalização que é condicionada pela ação da sociedade, que, para isso, se utiliza de mecanismos de organização regional histórica e culturalmente construídos, valendo-se da estruturação existente como base para definição de funções territoriais (BEZZI, 2004).

Numa regionalização que se baseie na ideia de região como espaço vivido, caminho apontado por Frémont (1980), a região integraria espaços sociais e lugares vividos, fazendo da região um 
"conjunto com estrutura própria" e a distinguindo de outras regiões, por representações específicas, consolidadas na percepção dos habitantes e dos estranhos à região. Assim, se a "identidade cultural" deve servir como paradigma para a definição dos limites de uma região, deve-se, em primeiro lugar, compreender os códigos de representação e significação dos grupos sociais que ali vivem. Desse modo, deve-se mais uma vez ressaltar que o regionalismo e o discurso regionalista representam posturas ativas dos grupos e agentes sociais no espaço regional e baseiam-se na cultura local vivida, que se serve das identidades culturais para encaminhar as aspirações destes grupos.

Concorda-se com as afirmações de Rogério Haesbaert (1997) de que a região não é um território em sentido amplo, mas um determinado tipo de território. A região é, sob esse ponto de vista, um recorte no espaço geográfico que manifesta sua diferenciação enquanto um território que é apropriado/controlado de uma maneira a um só tempo concreta e simbólica, através da consolidação de uma identidade territorial. A questão das identidades regionais, enquanto manifestações específicas de certo tipo de identidades territoriais, mantém-se insuficientemente explorada. No entanto, parece consensual que "identidades" se constroem sempre a partir do reconhecimento de uma alteridade. Isso, no entanto, só pode acontecer onde há interação, transações, relações ou contatos entre grupos. E se a cultura é o centro dos objetivos de uma Geografia que busca compreender o mundo vivido dos grupos humanos, é necessário reconhecer que o mundo vivido, mesmo que simbolicamente constituído, tem expressão material, não se devendo negar sua objetividade (COSGROVE, 2003). Assim,

o poder é expresso e mantido na reprodução da cultura. Isto é melhor concretizado quando é menos visível, quando as suposições culturais do grupo dominante aparecem simplesmente como senso comum. Isto às vezes é chamado de hegemonia cultural (COSGROVE, 1998, p. 105).

São essas variáveis que estão em jogo para a análise das políticas públicas no Brasil por um viés geográfico: escalas, território, poder, região, cultura, identidade e cidadania. Elas oferecem a oportunidade para a Geografia avançar nessa discussão, norteando-se por uma abordagem dialética e cultural para a análise das políticas públicas, como defendido nas primeiras seções deste artigo. Isso dá à Geografia também um papel ativo no campo político, voltada para a construção de um "novo modelo cívico", como apontado por Milton Santos (1992). Um modelo que aposte no homem como ser social e multidimensional e na recuperação da cultura, "com a substituição da ideia de recursos, noção estreita e enganadora, pela ideia de valor, que permite o encontro com o futuro" (SANTOS, 1992, p. 99).

\section{REFERÊNCIAS BIBLIOGRÁFICAS}

ARENDT, H. A Condição Humana. 10a Edição. Rio de Janeiro: Forense Universitária, 2000.

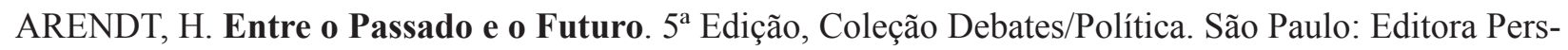
pectiva, 2002.

BEZZI, M. Região, uma (re) visão historiográfica. Da gênese aos novos paradigmas. Santa Maria-RS: Editora da UFSM, 2004.

CARDOSO, M. L. M. Desafios e potencialidades dos comitês de bacias hidrográficas. Ciência e Cultura, São Paulo, v. 55, n. 4, out./dez. 2003.

COSGROVE, D. A Geografia está em toda parte: Cultura e Simbolismo nas paisagens Humanas. In: Côrrea, R. L.; Rosendahl, Z. (Orgs.) Paisagem, Tempo e Cultura. Rio de Janeiro: EDUERJ, 1998. p. 93-122.

COSGROVE, D. Em Direção a uma Geografia Cultural Radical: Problemas de Teoria. In: Côrrea, R. L.; Rosendahl, Z. (Orgs.). Introdução à Geografia Cultural. Rio de Janeiro: Bertrand Brasil, 2003.

FRÉMONT, A. A região, espaço vivido. Portugal, Coimbra: Livraria Almedina, 1980.

HABERMAS, J. Mudança estrutural da esfera pública. Rio de Janeiro: Tempo Brasileiro, 1984. 
HAESBAERT, R. Des-territorialização e identidade. Niterói: EDUFF, 1997.

MITCHELL, D. Não existe aquilo que chamamos de cultura: Para uma reconceitualização da idéia de cultura em Geografia. Espaço e Cultura, Rio de Janeiro, n. 8, p. 31-51, agosto/dezembro, 1999.

RACINE, J. B.; RAFFESTIN, C.; RUFFY, V. Escala e ação. Contribuição para uma interpretação do mecanismo de escala na prática da Geografia. Revista Brasileira de Geografia, Rio de Janeiro, IBGE, n. 45, v. 1, p. 123-135. Jan/mar. 1983.

RUBIM, A. A. C. Políticas Culturais no Governo Lula. In: Rubim, A. A. C. (Org.). Políticas Culturais no Governo Lula. Coleção Cult, volume 6. Salvador: EDUFBA, 2010. p. 9-24.

SANTOS, J. L. dos. O Que é Cultura. $7^{\text {a }}$ edição. São Paulo: Editora Brasiliense, 1988.

SANTOS, M. O Espaço do Cidadão. 2a Edição. São Paulo: NOBEL, 1992.

SANTOS, M. Metamorfoses do Espaço Habitado. $3^{a}$ edição. São Paulo: Editora HUCITEC, 1994.

SILVA, S. C. B. de M. Teorias de localização e de desenvolvimento regional. Geografia, Rio Claro, v. 1, n. 2, p. 1-23, 1976.

SOTO, C.; CANEDO, D.; OLIVEIRA, G.; SALGADO, J. Políticas públicas de cultura: os mecanismos de participação social. In: Rubim, A. A. C. (Org.). Políticas Culturais no Governo Lula. Coleção Cult, volume 6. Salvador: EDUFBA, 2010. p. 25-47.

SOUZA, M. J. L. de. Os orçamentos participativos e sua espacialidade: uma agenda de pesquisa. Terra Livre. São Paulo, n. 15, 2000.

Trabalho enviado em agosto de 2011

Trabalho aceito em outubro de 2011 